\title{
PERSISTÊNCIAS DA FORMA URBANA Um estudo morfológico sobre o Eixo Maruípe
}

\author{
Flavia Ribeiro Botechia \\ Universidade Presbiteriana Mackenzie - São Paulo \\ Orientador: Profa. Dra. Maria Isabel Villac \\ flaviabotechia@yahoo.com.br
}

\section{RESUMO}

Neste artigo, que deriva de investigação de Doutorado, em desenvolvimento junto à Universidade Presbiteriana Mackenzie (São Paulo), propõe-se apresentar a estrutura da tese, detalhando os principais aspectos teóricos que dão suporte à construção (e verificação) das hipóteses e resultados parciais obtidos. O artigo está organizado em duas partes. Na primeira parte serão apresentados autores seminais referentes a temática sugerida percorrendo exemplos europeus e latino americanos. Na segunda parte o objeto empírico será apresentado juntamente com uma parte da pesquisa em andamento. Os dados da pesquisa serão trabalhados em uma linha do tempo regressiva, percorrendo os períodos históricos brasileiros da República, Império e Colônia, na qual se analisam fontes documentais cartográficas e textuais.

Palavras chave: persistência; forma urbana; Maruípe

\begin{abstract}
In this article, which derives from the PhD research under development at the Universidade Presbiteriana Mackenzie (São Paulo), it is proposed to present the thesis reasoning structure, detailing the main theoretical aspects that support the construction (and verification) of the hypotheses and partial results obtained. This article is organized in two parts. In the first part, will be presented seminal authors referring to the suggested theme, traversing European and Latin American examples. In the second part the empirical object will be presented along with a part of the research in progress. The research data will be worked in a regressive time line, traversing the Brazilian historical periods of the Republic, Empire and Colony, in which documental cartographic and textual sources are analyzed.
\end{abstract}

Key words: persistence; urban form; Maruípe 


\section{INTRODUÇÃO}

Autores como Morris (1979), Kostof (1999/2009), Portas (2005), Dias Coelho (2014) se opõem à noção de cidade como obra acabada. Com esta perspectiva contribuem ao entendimento de que no tecido urbano coexistem diferentes elementos da forma urbana, produzidos em diferentes tempos e com ciclos de vida autônomos. Dessincronização elementar que se relaciona à, pelo menos, dois processos morfológicos (Conzen, 1960): o de contínua transformação, como o que acontece mais frequentemente com edificações e usos; e outro que lida com a estagnação das estruturas, principalmente, no que se refere ao traçado e ao parcelamento fundiário.

Alguns termos podem ser associados ao processo de estagnação, temática que interessa à pesquisa de doutorado (em andamento) tais como inércia, permanência, persistência. Entretanto, estes não devem ser tratados como sinônimos. Para estudar os elementos que atravessam diferentes períodos, propõe-se como chave de interpretação trabalhar a noção de persistências morfológicas [PER-, da preposição do latim, "através de", "por entre"; -SISTERE, "permanecer firme", "ficar firme"], cuja etimologia indica "ser constante, perseverar, insistir"; do latim persistére; persistência (sec. XVII); persistente (sec. XVII).

Ao observar nos traçados urbanos vestígios de épocas anteriores, as evidências materiais apontam para edifícios, catedrais, edificações ordinárias; entretanto, não se deve esquecer que os elementos bidimensionais também possuem níveis de perenidade. É assim que um antigo caminho pode ser a forma pretérita do eixo de uma rodovia; canais de irrigação ou drenagem, de atuais vias urbanas pavimentadas; tramas agrícolas, de limites de lotes ou quarteirões. Com esse raciocínio seria possível identificar indícios, através da análise documental, de que a forma atual da cidade é resultado de um processo de permanência (sedimentação) e persistência (deformação) de estruturas anteriores sejam elas materiais ou mesmo imateriais.

Do mesmo modo nota-se que existem regras que proporcionariam uma tendência à estagnação. Especificamente no caso da "persistência da planta" (Lavedan,1926), teóricos afirmam que um caminho antigo persiste por sua importância como direção de uma rota comercial, pela estabilização da propriedade da terra ao longo deste eixo, mas também, pelas características formais do relevo e dos cursos d'água.

Neste artigo, que deriva de investigação de Doutorado, em desenvolvimento junto à Universidade Presbiteriana Mackenzie (São Paulo), propõe-se apresentar a estrutura da tese, detalhando os principais aspectos teóricos que dão suporte à construção (e verificação) das hipóteses e resultados parciais obtidos. Para tanto, organiza-se o artigo em duas partes. Na primeira parte serão apresentados autores seminais referentes a temática sugerida, percorrendo exemplos europeus e latino americanos. Na segunda parte 0 objeto empírico será apresentado, juntamente com uma parte da pesquisa que se desenvolve. Os dados obtidos foram trabalhados em uma linha do tempo regressiva, percorrendo os períodos históricos brasileiros da República, Império e Colônia, na qual se analisam fontes documentais cartográficas e textuais. Ao final do artigo serão apresentados resultados e conclusões parciais.

\subsection{A tese}

O principal objetivo da tese é identificar os elementos morfológicos de maior persistência (e também permanência) na longa duração, a partir da análise de objeto empírico. Para tanto, a estratégia metodológica adotada está amparada na abordagem morfológica histórico-geográfica (Kropf, 2009), no emprego dos métodos comparativo, histórico regressivo e de individualização dos elementos da forma urbana.

No desenvolvimento da investigação, norteada pelo objetivo pretendido, partiu-se da hipótese de que dentre os elementos urbanos, é o elemento bidimensional, em especial a rua, aquele com maior longevidade, portanto, dentre outros o mais persistente no tempo. Lança-se notadamente e conjuntamente também uma conjectura: dados sociais, jurídicos, econômicos, políticos não podem ser invocados como única explicação da longevidade das formas, pois há aspectos materiais e físicos que devem ser considerados na avaliação da persistência morfológica.

Propôs-se verificar esta hipótese através do estudo de um eixo viário específico, formado por um conjunto de avenidas localizadas a Nordeste da cidade Vitória (Espírito Santo, Brasil) que aqui se denominará por "Eixo Maruípe". Justifica-se esta escolha pois acredita-se também por hipótese que o Eixo Maruípe poderia ser a persistência de parte de uma estrada do período do Império do Brasil que no seu trajeto atravessava a ilha de Vitória e era denominada Estrada Geral da Costa. Como condição geográfica o município de Vitória 
constitui-se ponto central da Região Metropolitana e é constituído em parte de uma ilha principal, com área de $29.31 \mathrm{~km}^{2}$, além de outra parte continental, situada a Norte, com $39.66 \mathrm{~km}^{2}$. E durante quatro séculos o único ponto de interligação físico entre ilha e continente se deu através do estreito do Canal "da Passagem", localizado a Nordeste.

As fontes documentais primárias utilizadas na pesquisa foram cartográficas e textuais. Destas fontes, buscouse dar protagonismo à análise cartográfica pois foi o aparecimento de mapas detalhados e fotografias aéreas, no final do século XIX, que permitiu a historiadores, geógrafos, arquitetos, arqueólogos compararem plantas da cidade em tempos distintos e observarem os processos que incidem sobre as formas do parcelamento, inclusive a sua duração. Entretanto, em referência ao caso de estudo escolhido, admite-se que nos séculos anteriores ao século XIX, os indicativos de vestígios da materialidade encontram-se registrados também em documentos como Relatórios de Governo e relatos de viajantes.

Em relação ao estudo empírico, o procedimento para coleta de dados passou por dois estágios. O primeiro compreendeu etapas de identificação de documentação, recolha em arquivos, periodização, georeferenciamento e redesenho para equalização das representações (no caso das plantas) utilizando o software QGIS versão 2.6.1. No segundo estágio realizou-se a interpretação das informações fazendo conexão entre as diferentes fontes documentais. Neste procurou-se analisar o traçado urbano, à escala do território e à escala do município, através da reconstituição cartográfica conjectural; comparação entre as reconstituições de tempos distintos em escalas idênticas e sistematização de dados obtidos.

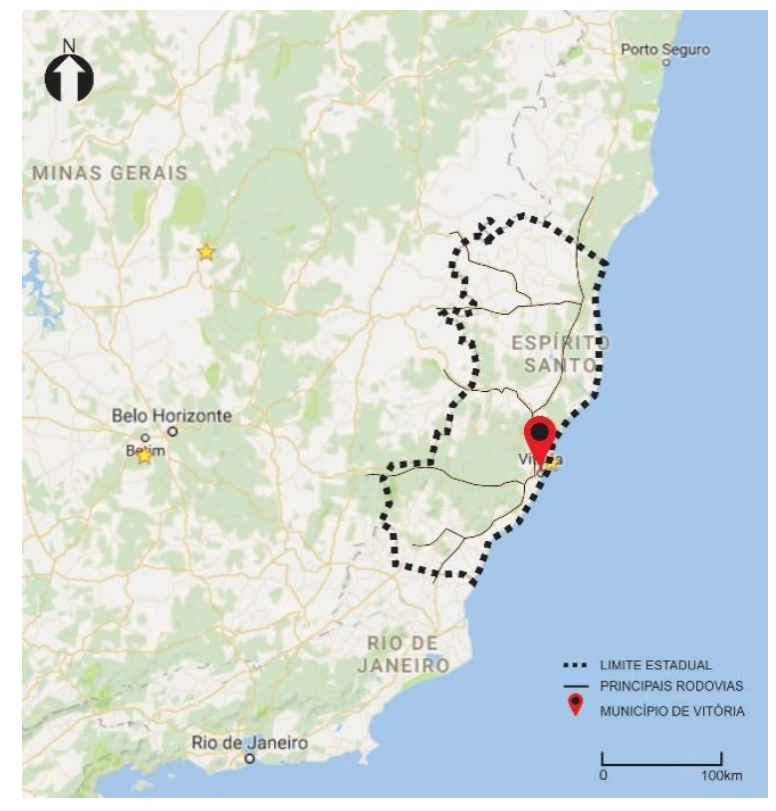

Mapa do Estado do Espírito Santo, Brasil.

Fonte: Elaborado pelo autor a partir de base do Google Maps.

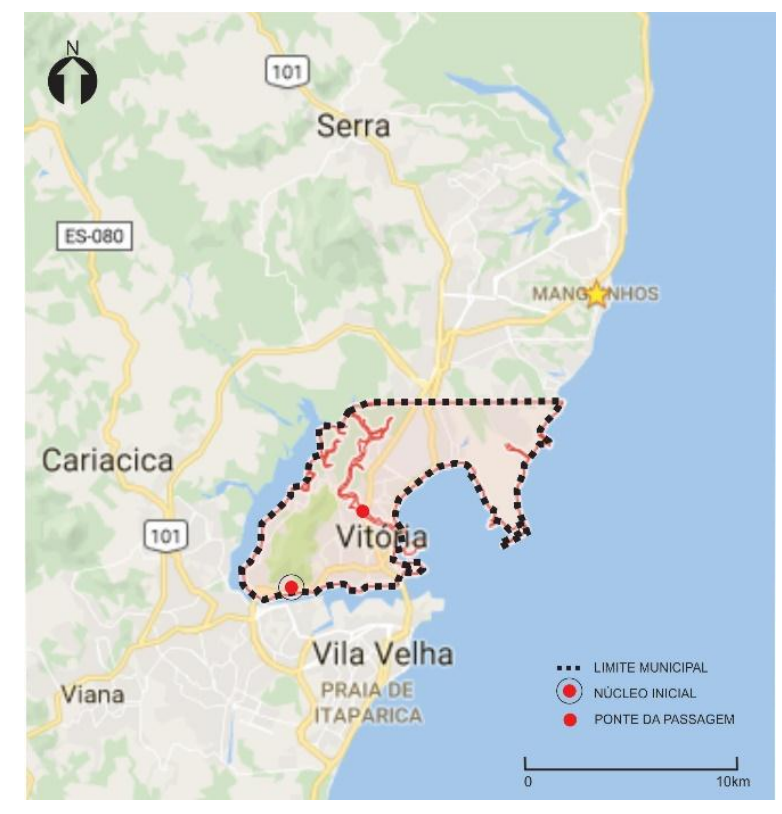

Mapa do município de Vitória.

Fonte: Elaborado pelo autor a partir de base do Google Maps.

\section{PERSISTÊNCIAS MORFOLÓGICAS}

Os autores fundamentais para entendimento do processo morfológico da persistência, ao se deter sobre o caso europeu, são Pierre Lavedan (1926), MRG Conzen (1960) e Pierre Pinon (2008). Entretanto, registra-se que se trata de um recorte, pois há outras bibliografias como os estudos elaborados pelo grupo FormaUrbisLab, coordenado pelo Professor Dr. Carlos Dias Coelho.

O historiador francês Pierre Lavedan (1926), discípulo de Marcel Poète, é reconhecidamente um dos primeiros teóricos a fazer um estudo sistemático e aplicado sobre a persistência da forma urbana. Ao identificar os elementos geradores da planta da cidade através de análises cartográficas, o autor identifica uma lei, "não universal, nem absoluta", a qual denomina "Loi de la Persistence du Plan" (Lei da Persistência da Planta). Segundo esta lei, formulada por Lavedan, as ruas de uma cidade valem pelo tempo em que foram construídas, 
mas podem perdurar além deste tempo. Com isso, o conhecimento da planta urbana atual contribui no conhecimento e interpretação das plantas de períodos anteriores pelo simples fato de que pode ser estabelecida uma conexão comparativa entre ambas. E esta conexão é feita a partir dos elementos que permanecem.

O ponto inicial desta identificação se deu pela observação de três tipos de cidades, aquelas "paradas" no tempo que tendem a cair no ostracismo, as que foram destruídas por eventos violentos como guerras ou catástrofes naturais e, ainda, aquelas que sofreram transformações sistemáticas. Lavedan, portanto, testa o argumento de que as formas urbanas são transmitidas no tempo e faz um estudo das plantas de seis cidades tentando identificar casos de persistências: uma estrada no caso de Tell el Amarna, o plano da antiga cidade de Salonique, caminhos medievais de Fourvières, a muralha medieval convertida no caminhamento das avenidas em Beaumont, além de outros exemplos em Périgord, Cambridge, Paris e Munique. Após uma série de estudos aplicados e comparativos, como uma das conclusões o autor observa que no caso das cidades refeitas sem a intervenção direta do Estado e num intervalo temporal onde destruição e reconstrução estão próximas, há uma forte tendência à recuperação "espontânea" (através da memória) da forma pretérita.

Pierre Pinon (2008), anos mais tarde, com a publicação do artigo "Défense et illustration de la "Loi de persistance du plan", recupera a escrita de Lavedan e identifica a persistência de fragmentos de tecidos urbanos preexistentes na análise de plantas de algumas cidades francesas de fundação romana. Faz isso defendendo como método de reconstituição da materialidade do traçado, a "prospecção" retrospectiva feita através das fotografias aéreas, mapas cadastrais e análise morfológica dos tecidos urbanos.

Procedendo então com a análise "retrospectiva das plantas cadastrais" de Bourges, Amiens, D'Autin, Limoges e Paris, Pinon recupera o que ele denominou por "três leis da persistência da planta" e também as diferenças conceituais entre persistência e permanência (tratadas também por Lavedan no texto de 1926). As três leis fundamentais referem-se à possibilidade de se fazer um estudo desta natureza. Portanto segundo o autor (Pinon, 2008: 129-132), para tanto, é necessário que se verifique antes de iniciar qualquer pesquisa: a existência de tipos de plantas urbanas (de matriz colonial, ortogonal, romana, etc., a depender da história da cidade); o fenômeno da conservação do traçado (identificação preliminar de evidências topográficas, implantação de edifícios, antigos caminhos); e a possibilidade de se reconstituir as plantas originais.

Para Pinon, no caso da persistência, a estrutura do elemento urbano se modifica, quase sempre no sentido de uma deformação. $O$ autor faz ainda uma distinção entre categorias, as quais o autor denomina 'persistência de traçado' (fronteiras fragmentadas modernas; parcelas de ruas antigas, alinhamentos) e 'persistência de direção' (limites de áreas modernas paralelos às parcelas de ruas modernas). A persistência, considerando os fatores colocados, poderá aparecer sob a forma de fragmentos e vestígios. Pinon evidencia o papel significativo das ruas nesta identificação, mas também do parcelário sendo este último particularmente estável, se constituindo numa espécie de 'memória das formas urbanas'.

O geógrafo alemão Conzen (1960), ao se deter sobre análises morfológicas de pequenas cidades e vilas inglesas identificou, por sua vez, a existência de processos morfológicos que agem sobre a substituição das formas urbanas, em três escalas: da planta da cidade, da edificação e do uso. Pelo menos dois verbetes do "Glossário de termos técnicos", elaborado por este autor, fazem referência à persistência: 'Persistence of inherited forms'; e 'Systematic differentiated persistence of forms (principle of)'. Na definição destes termos, Conzen afirma que o "plano urbano" (composição bidimensional da planta da cidade) é dentre os elementos morfológicos aquele mais persistente e que a longevidade das formas urbanas está relacionada ao seu uso, pois,

"[...] when inherited forms continue to be functionally suitable to current and changed conditions of town life, or survive through material inertia, sometimes in a ruinous state. Since the length of persistence of forms has commonly depended on a great number of variable factors, it has tended to vary greatly by form complex and in spatial structure" (Conzen, 2004: 253).

Na América Latina, alguns autores procedem com investigações correlatas. Neste artigo foram selecionados dois deles como referencial teórico. Marina Waisman em "O interior da História. Historiografia arquitetônica para uso de latino-americanos" (2013) enumera dez conceitos instrumentais para o desenvolvimento de estudos históricos e prática arquitetônica, dentre os quais "as durações históricas".

Citando Fernand Braudel, Waisman afirma que a teorização sobre as temporalidades da História, de curta e longa duração, pode ser aplicada ao estudo da cidade latino-americana, tanto no campo das materialidades 
quanto no campo das ideias. Quanto ao estudo das materialidades, a autora destaca haver exemplos de "permanência relativa", mas também (fazendo referência específica ao Chile) há movimentos de superposição de tramas. E se mesmo os lotes cadastrais não forem invariáveis, a persistência se observa em tipologias edilícias (mais do que na trama).

No Brasil, destaca-se o trabalho desenvolvido pelo Professor Dr. Nestor Goulart Reis (2004) ao estudar as características tipológicas e transformações de São Paulo na passagem de "Vila à Metrópole". Nesta publicação o professor dialoga com a hipótese de que estruturas anteriores podem ter condicionado, pela continuidade, estruturas subsequentes. Desse modo é possível identificar sinais na análise cartográfica da direção de a muralha colonial, que já não existe mais embora persista como o traçado das ruas da cidade. Em outra pesquisa sobre a Rodovia Anhanguera (2014), também em São Paulo, o autor busca, dentre outros aspectos, demonstrar que a atual Rodovia, uma das saídas de São Paulo sentido Goiás, é a permanência de fatores tangíveis como uma trilha indígena; e intangíveis como as memórias. Ainda em outro livro, Quadro da Arquitetura no Brasil (1970/2014), o autor ao tratar das relações entre lote e edificação nas cidades brasileiras, trabalha sobre a dessincronização elementar e suas consequências.

Dentre os diferentes casos de persistência citados e identificados nas leituras realizadas, aquele sobre a persistência formal de um caminho antigo no traçado urbano atual ganhou protagonismo e interesse destacados. Esta relação entre preexistência e forma atual poderia ser identificada na cidade de Vitória e seus arredores? A falta de estudos com este perfil sobre a região, em paralelo à identificação de cartografias nos arquivos locais que possibilitassem este tipo de investigação, levou ao desenvolvimento de um estudo aplicado que se apresenta, em parte, a seguir.

\section{O EIXO MARUÍPE}

$\mathrm{Na}$ tentativa de individualizar um objeto específico que pudesse ser estudado em Vitória e arredores, considera-se que o ponto de partida foi a pesquisa nas entidades custodiadoras sediadas no município como - Arquivo Público Estadual, Arquivo Geral do Município, Biblioteca Estadual, Biblioteca Central da Universidade Federal do Espírito Santo, Biblioteca do Instituto Jones dos Santos Neves. Dentre toda a documentação identificada e recolhida nestas consultas, estima-se que três documentos (dois deles de natureza cartográfica, e um textual) contribuíram fortemente tanto à identificação do objeto quando à construção da hipótese de trabalho.

Um deles é uma cartografia produzida, em 1896, pela Comissão de Melhoramentos da Capital denominada 'Esboço da planta da ilha de Vitória'. Como parte do conjunto cartográfico que compõe o 'Plano de um Novo Arrabalde' esta referida carta, colorida, produzida a escala 1/20.000 teve como objetivo representar numa planta de situação do município, o novo bairro projetado por Francisco Rodrigues Saturnino de Brito. Acompanha este documento, uma legenda. Dentre as indicações constantes nesta legenda, há a convenção gráfica de uma 'linha', na cor preta, indicada como "caminho para tropas". Em paralelo a este caminho encontra-se representado um rio e as inscrições Maruhype e Jucutuquara. Em outra cartografia denominada "Estrada de rodagem (...)", do mesmo conjunto anterior e, portanto, elaborado mesmo autor, consta a representação gráfica de um projeto viário (da tal estrada) que seguia desde o núcleo urbano existente até o novo arrabalde projetado. Sobreposta ao alinhamento da nova via, na planta indica-se uma linha preta sinuosa junto à indicação "estrada antiga".

Seria pouco se não fosse possível mesmo que à primeira vista notar que esta 'linha preta', tanto na primeira quanto na segunda planta com a indicação 'caminho de tropas' e/ou 'estrada antiga', segue (mais ou menos) a direção das atuais Avenidas Vitória e Maruípe ${ }^{1}$ em suas retas e curvas. Colocou-se, então, claramente uma pergunta: de que tempo seriam as avenidas que percorrem a região de Maruípe? Se em 1896 já existiam, quem as projetou? Como e quando foram criadas?

O terceiro documento foi o livro sobre transporte rodoviário denominado "A Trilha Sagrada". Neste livro Sartório (2007) indica a existência de algumas estradas gerais e outras vicinais na Província do Espírito Santo, durante o breve período entre 1822 e 1889 que durou o Império no Brasil. Buscando respostas, olhando outros mapas, lendo outros livros, chegou-se a uma hipótese para ser investigada: a Avenida Maruípe poderia ser a

\footnotetext{
${ }^{1}$ Maruípe aparece como uma toponímia da época colonial utilizada para indicar uma região, um bairro, um rio, uma fazenda, uma avenida e uma ponte na cidade de Vitória. Segundo consta Maruípe é um termo oriundo da língua tupi e significa 'no rio dos mosquitos', junção dos termos mberu ("mosca"); $y$ ("água"); pe ("em").
} 
persistência de um trecho de uma estrada, correspondente a saída terrestre norte da ilha de Vitória, nomeadamente a Estrada Geral da Costa.

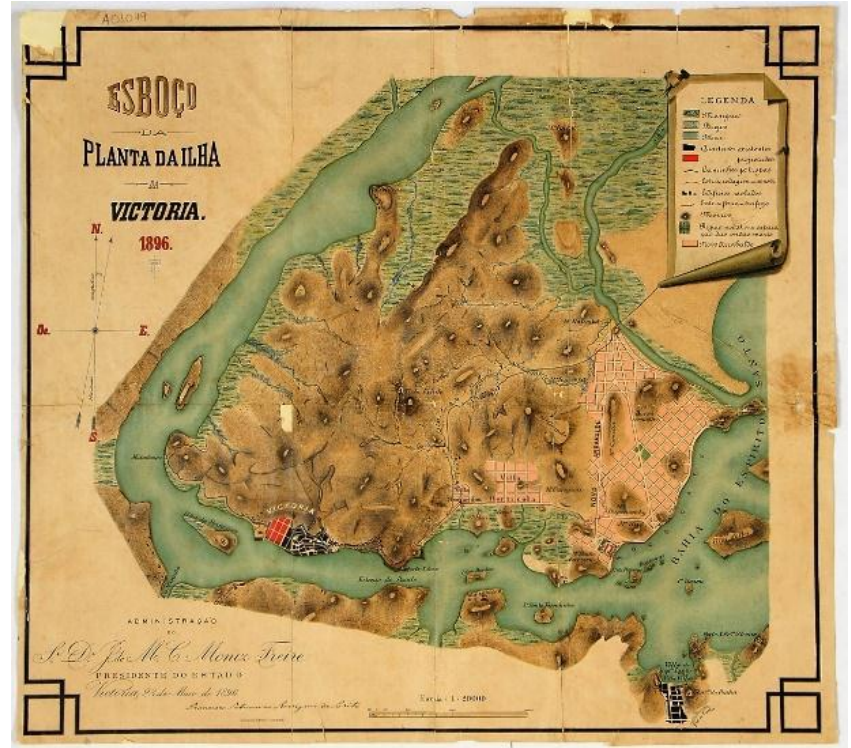

Documento cartográfico 'Esboço da planta da ilha de Vitória'. Escala: 1/40.000. Autor: Comissão de Melhoramentos da Capital/ Engenheiro Chefe Francisco Rodrigues Saturnino de Brito.

Fonte: Arquivo Público do Espírito Santo, 2015.

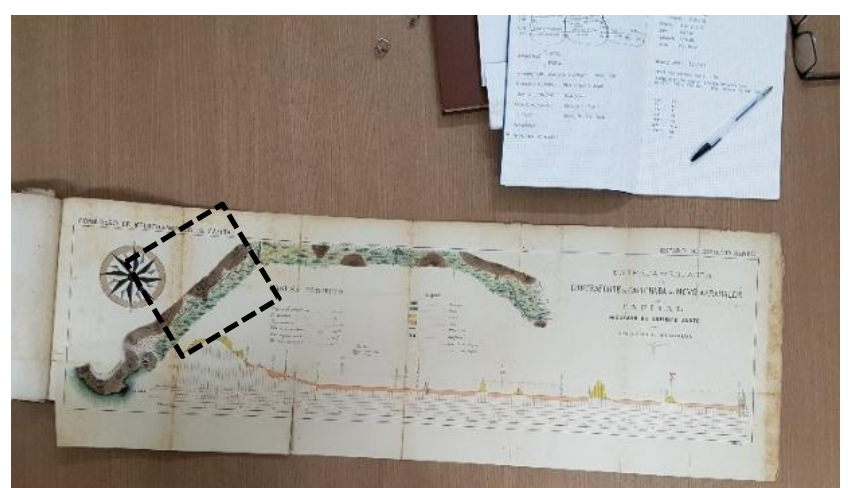

Fotografia do documento cartográfico "Estrada de rodagem do Contraforte da Capichaba ao Novo Arrabalde da Capital do Estado do Espírito Santo". Planta e perfil longitudinal. Escala: 1/4.000. Autor: Comissão de Melhoramentos da Capital/ Engenheiro Chefe Francisco Rodrigues Saturnino de Brito.

Fonte: Foto elaborada pelo autor em consulta ao Acervo do Arquivo Público do Espírito Santo, 2015. Intervenção com identificação do trecho ampliado.

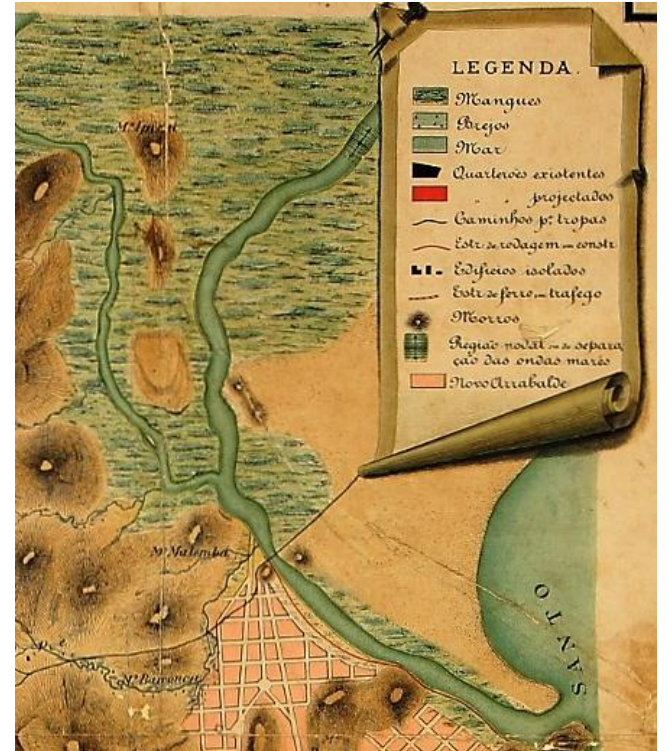

Detalhe da legenda da carta 'Esboço da planta da ilha de Vitória'.

Fonte: Corte elaborado pelo autor a partir de imagem do documento original, 2015.

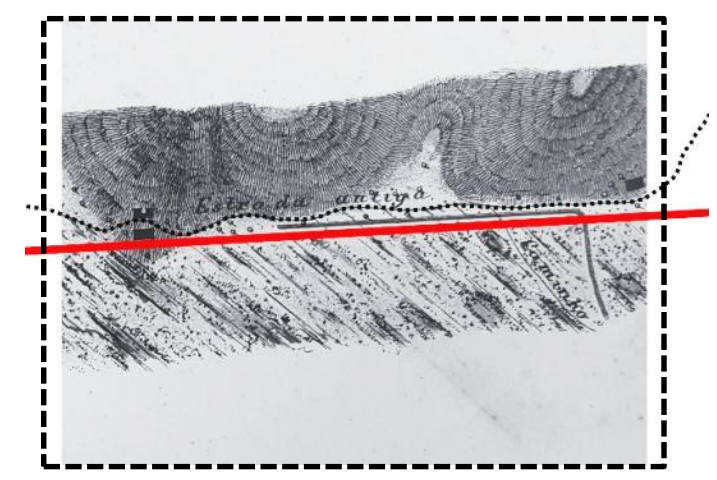

Detalhe da inscrição "Estrada antiga" constante na planta "Estrada de rodagem (...)".

Fonte: Elaborado pelo autor a partir de imagem do documento original, 2015.

Tendo esta hipótese de partida, procurou-se por indicativos sobre a formação e estruturação do território, utilizando-se a restituição cartográfica regressiva para comparar aspectos formais do eixo viário em questão. Para fins de interpretação denominar-se-á o objeto de estudos por Eixo Maruípe. Este compreende uma sequência de vias que vão desde a região central (entroncamento das Avenidas Jerônimo Monteiro e Princesa Isabel) até a Ponte da Passagem, a saber: Avenidas Vitória, Paulino Muller e Maruípe, além do trecho final, qual seja, a Rua Dona Maria Rosa. Este eixo será previamente dividido em três trechos para fins de descrição e análise, justificado pelas inflexões formais e toponímias:

- Trecho 01 - da Rua Barão de Monjardim até a Praça Asdrúbal Soares (compreende a Avenida Vitória);

- Trecho 02 - da Praça Asdrúbal Soares até a entrada do bairro Fradinhos (compreende a Avenida Paulino Muller);

- Trecho 03 - da entrada do bairro Fradinhos até a Ponte da Passagem (compreende a Avenida Maruípe e Rua Dona Maria Rosa). 


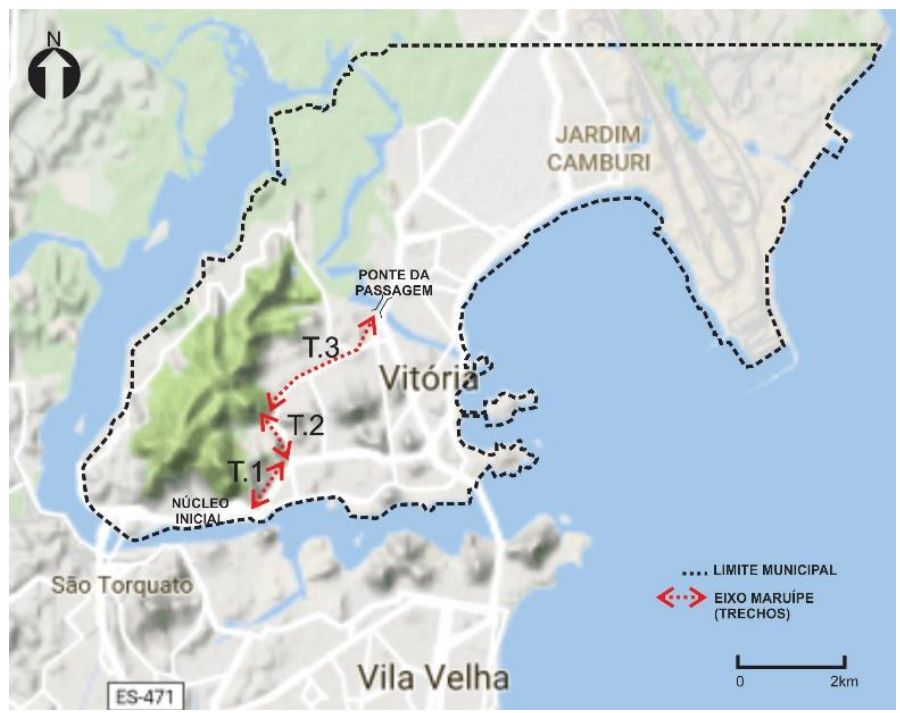

Mapa do município de Vitória, com identificação do Eixo Maruípe subdividido em três trechos.

Fonte: Elaborado pelo autor a partir de base do Google Maps.

\subsection{Análise documental retrospectiva}

Neste item, apresenta-se uma parte da análise documental elaborada sobre o Eixo Maruípe. Esta análise segue uma linha do tempo retrospectiva abordando primeiramente as fontes do período da República (1889atual), depois do Império (1882-1889) e, por fim, do período Colonial (1500-1822). Cada um destes períodos foi trabalhado na tese percorrendo as fontes cartográfica, textual e iconográfica, porém, neste artigo serão apresentadas parcialmente as informações obtidas.

Durante a República, a ilha de Vitória progressivamente foi urbanizada. O núcleo de povoamento de matriz colonial portuguesa encontrava-se em 1889 restritos a cerca de $6 \%$ da área total da ilha e as demais terras. No limite insular, além do núcleo 'urbano' as demais terras podem ser descritas como de propriedade do Governo ou de poucos particulares, tendo caráter suburbano ou rural (como era o caso das fazendas) cujo relevo era característico pelo bioma "Mar de Morros"2, tendo ainda uma cota de áreas alagadas (ou de charco). A passagem do rural ao urbano se deu lentamente e alguns vestígios anacrônicos podem ser identificados.

A representação das Plantas de Cadastro elaboradas nos anos de 1911, 1946, 1979 (início, meio e fim do século $X X)$ e documentos cartográficos complementares foram fonte documental primária consultada, e redesenhada, para remontar aspectos morfológicos do Eixo Maruípe ${ }^{3}$ durante a República.

A partir do redesenho da Planta Cadastral de 1911, observou-se que este Eixo, objeto de análise em questão, entremeava uma região suburbana, percorrendo as linhas de vale e acompanhando a linha sinuosa do sopé das montanhas. Já tinha como ponto inicial a Rua Barão de Monjardim (Capixaba) e como limite final, a Ponte da Passagem. No trecho 01, paralelo a um sinuoso caminho existente, construiu-se uma Avenida (aquela projetada por Saturnino de Brito). A partir do trecho 02, nos limites do bairro Jucutuquara, o eixo do caminho mantinha um paralelismo em relação aos rios existentes na região (ainda com conformação natural) e a geometria não dominava seus aspectos morfológicos.

A característica formal de então se assemelhava mais a uma estrada do que propriamente a uma via urbana (com calçadas, meio fio ou posteamento), e passava por dentro de propriedades privadas como as Fazendas Jucutuquara e Maruípe. Não por acaso o 'melhoramento' de ruas e das estradas, como retificação e

\footnotetext{
${ }^{2}$ AB'SABER, A. Os domínios de natureza no Brasil. São Paulo: Ateliê Editorial, 2003.

${ }^{3}$ A cartografia principal utilizada nesta etapa corresponde aos documentos: Carta cadastral da cidade de Vitória com curvas de nível (...) nos anos 1909 a 1911, elaborada por Dr. Augusto Ramos (1 planta; sem escala); Levantamento Cadastral e semi-cadastral, elaborados ambos pela Empreza de Topografia Urbanismo e Construção (E.T.U.C.) (1946, 2 conjuntos às escalas 1/1.000 e 1/500); Levantamento cadastral; empresa Maplan S.A (1979, 1 conjunto à escala 1/2.000). Fonte: Arquivo Público Municipal; Arquivo Público do Espírito Santo. Para o redesenho foram utilizadas cartografias complementares.
} 
pavimentação, foi tema frequente no discurso dos Presidentes de Estado durante a 1a. Republica (18891930), tendo sido constituído no Governo Aristeu Borges de Aguiar (1928-1930), por exemplo, o "Plano de Estradas de Rodagem".

Em meados do século, apoiado no redesenho da Planta Cadastral de 1946 (e documentos auxiliares), o Eixo Maruípe é representado ora como 'rodovia', ora como 'caminho carroçável'. Das 34 pranchas identificadas, à escala 1/1.000, foram selecionadas aquelas que continham referência ao Eixo. Com o redesenho, além de consulta à outros documentos, verificou-se que a forma urbana do período é resultado de uma série de ações pretéritas promovidas pelo agente público estadual que incluíram: retificação e urbanização das estradas convertendo-as em Avenidas e Ruas; canalização dos rios e córregos; drenagem do solo; parcelamento das glebas maiores e suburbanas em propriedades menores e urbanas (como chácaras ou loteamentos).

O levantamento cadastral subsequente, executado em 1979 pela empresa Maplan S.A. por solicitação da Prefeitura de Vitória, utilizou-se da metodologia da aerofotogrametria para fins cadastrais e topográficos. Das ortocartas geradas a partir do voo, representadas na escala $1 / 2.000$, foram selecionadas as pranchas referentes ao Eixo Maruípe para redesenho e interpretação. Através desse procedimento foi possível compreender que o trecho 01 se consolidou em relação à forma da avenida (largura e extensão), se intensificou a ocupação de suas bordas com parcelamentos e construções, recebendo sucessivamente elementos de mobiliário urbano (calçada, posteamento). No trecho 02, que corresponde ao bairro Jucutuquara, a via principal recebia o nome de Rua José Malta possuindo cerca de 20 metros de largura e o córrego que passava pelo centro estava completamente tamponado, já correspondente a seu aspecto atual. No início do trecho 03, entre Fradinhos e a Ponte da Passagem, observou-se o início da construção de uma via paralela à Avenida Maruípe, com objetivo de alargamento e retificação.

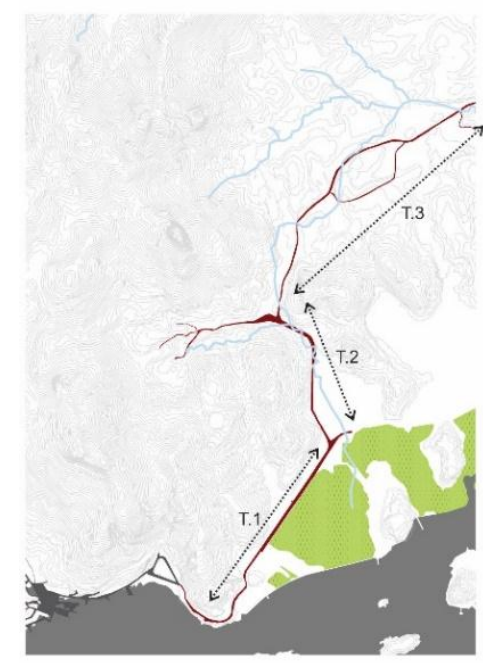

Planta conjectural 1911

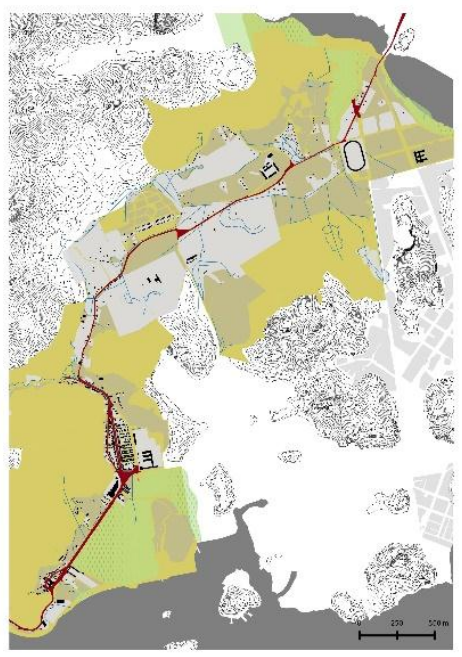

Planta conjectural 1946

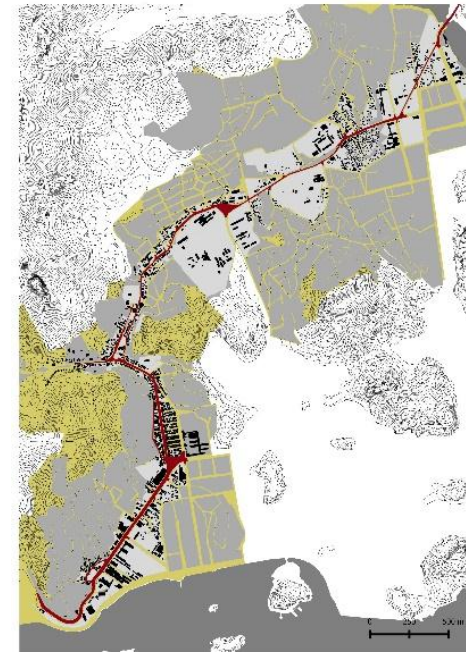

Planta conjectural 1979 Plantas conjecturais dos anos de 1911, 1946 e 1979 do município de Vitória, com identificação em destaque para a direção de parte do Eixo Maruípe.

Fonte: Elaborado pelo autor a partir do georeferenciamento de plantas cadastrais utilizando software QGIS versão 2.6.1.

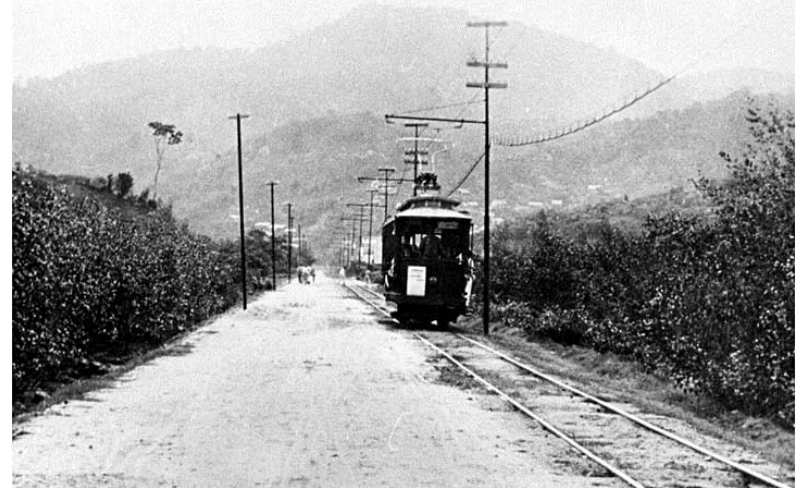

Fotografia da Avenida Vitória, em 1920: retificação do traçado e implementação da linha de bonde. Fonte: Arquivo Público do Espírito Santo. 
Se por um lado a ação de agentes públicos, durante o século XX, desenhou e executou a forma urbana deste Eixo em práticas sucessivas, sobrepostas e acumulativas registradas na cartografia, por outro lado, em nenhuma das Mensagens de Presidentes de Estado, ou outra fonte textual consultada, indica-se que a Avenida (ou estrada ou via) foi 'aberta' ou 'construída' na República. Não foram identificados também relatos de aspectos como grandes alterações de trajeto, envolvendo desapropriações, salvo especificamente em parte do 'Trecho 03'. O que se nota é sempre um registro de intervenções de melhoramento, alargamento, pavimentação e retificação do eixo existente, incluindo as inúmeras dificuldades técnicas e financeiras...O que nota é uma persistência da direção deste eixo.

Assim, esta direção que vai desde o núcleo inicial de povoamento até a "Ponte da Passagem" localizada à Nordeste, não é oriunda do período republicano. Poderia ser anterior a isso? Pelo que se pode verificar, já no Império havia estradas gerais e estradas vicinais, suporte físico para deslocamentos terrestres de comerciantes, viajantes, carteiros, tropas, registradas através de textos e plantas. Vejamos.

No período do Império do Brasil pelo Espírito Santo passavam quatro estradas gerais interprovinciais, nomeadamente, Estrada Geral da Costa (sem data de inauguração identificada); Estrada de São Pedro de Alcântara (ou Estrada do Rubim, 1814); Estrada de Itapemirim (1830); Estrada de Santa Thereza (1848-49). Destas, pelo que se conclui a partir da análise cartográfica e documental, somente a Estrada da Costa passava dentro dos limites da capital da Província, a cidade de Vitória. Importante eixo da circulação para o perfil comercial que se dava no Império, a Estrada Geral da Costa é mencionada em diversos Relatórios de Presidentes da Província, além de ser indicada em algumas das cartografias do mesmo período.

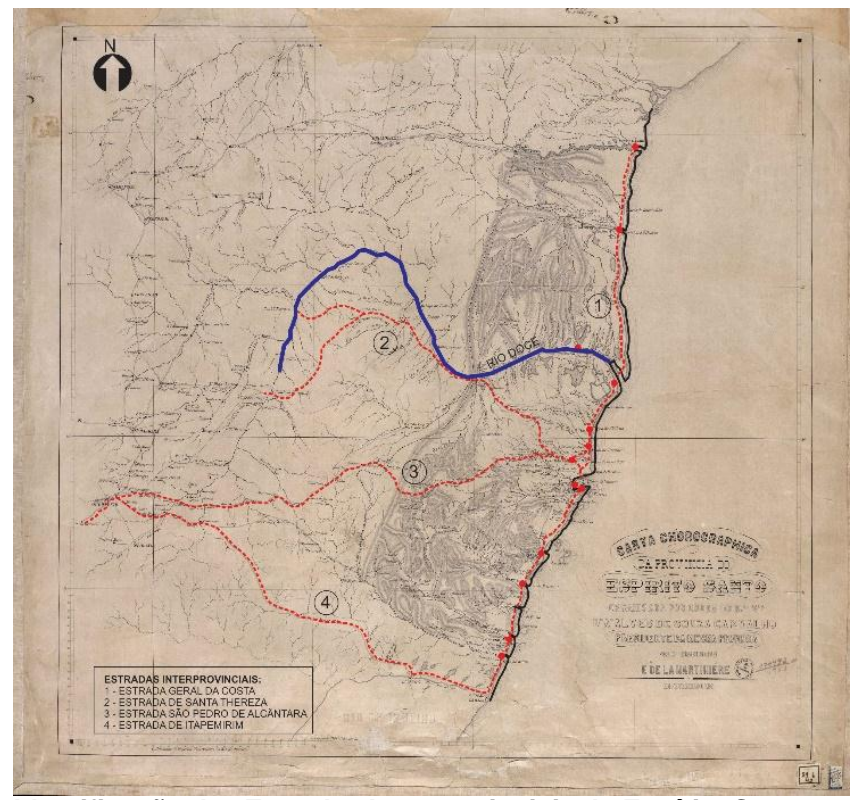

Identificação das Estradas Interprovinciais do Espírito Santo na Carta Chorographica da Província do Espírito Santo (1861). Fonte: Intervenções elaboradas pelo autor sobre imagem do mapa original fornecida pela Biblioteca Nacional do Brasil.

Das sete cartas analisadas mais detidamente, a Estrada Geral da Costa foi considerada em cinco delas, a saber: as cartas do Espírito Santo produzidas nos anos de 1817, 1850, 1861, 1866, 18784. Este registro, alinhado aos registros textuais, comprova a existência deste elemento e a importância na conexão terrestre entre núcleos de povoamento. Mais do que isso uma aproximação à ilha de Vitória, demonstra que esta Estrada passava por dentro dos limites insulares e possuía a direção do Eixo Maruípe. Sua importância reside na distribuição de mercadorias desde o interior até o Porto de Vitória, principalmente no trecho dentro da ilha de Vitória, ou seja, no mesmo Eixo Maruípe.

\footnotetext{
4 A cartografia utilizada nesta etapa corresponde aos documentos: Atlas "Guia de Caminhantes" (1817); Carta Topographica e Administrativa da Província do Espirito Santo erigida sobre os documentos mais modernos (1850); Carta Chorographica da Província do Espirito Santo (1861); Mappa Geral da Província do Espirito Santo relativo as colônias e as vias de comunicação (1866); Planta da parte da Provincia em que estão comprehendidas as colônias, organizada na Inspetoria das Terras e Colonisação pelos engenheiros C. Cintra e C. Rivièrre (1878). Fonte: Biblioteca Nacional do Brasil.
} 


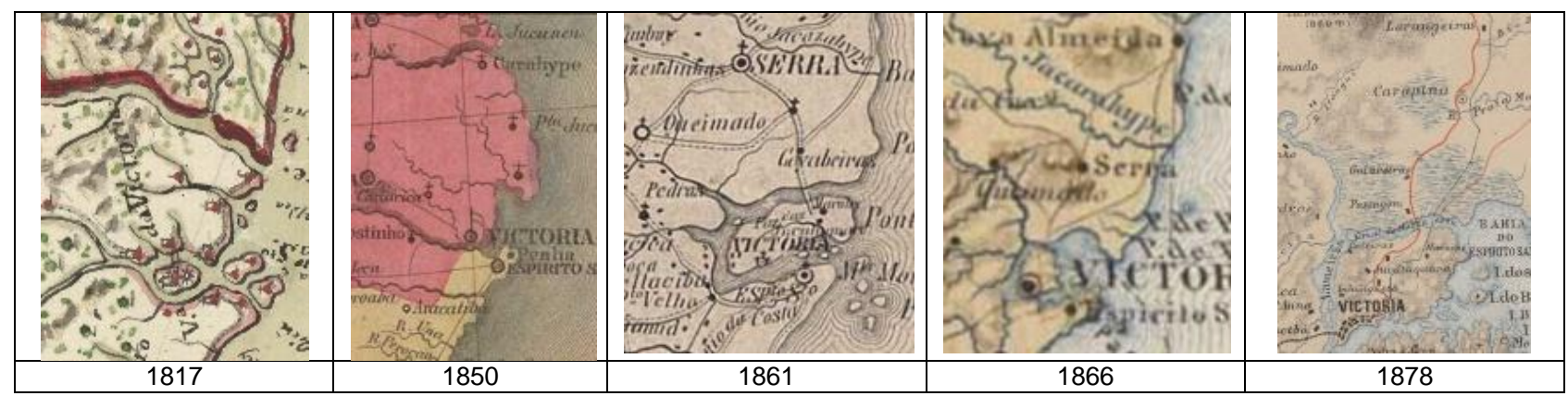

Recortes comparativos da cartografia analisada entre os anos de 1817 e 1878, detalhando a direção da Estrada Geral da Costa a escala da ilha de Vitória.

Fonte: Elaborado pelo autor a partir das imagens das cartografias pesquisadas.

Uma das primeiras referências a esta Estrada é atribuída, por Sartório (2007), ao Governador Francisco Alves Rubim (1812-1819), que a descreve como um eixo à beira mar que interliga as Capitanias do Rio de Janeiro à Bahia, tendo Vitória como uma espécie de ponto médio: "A estrada geral corre junto ao mar, ou próximo a elle (....)" (Rubim, 1840/ 2003: 20); e em outro trecho:

"Da povoação de Linhares à barra do Rio Doce, na margem do Norte tem 8 legoas; 1 legoa acima se acha estabelecido com lavouras, e gado Antônio José Martins, homem branco, casado, com uma família de 16 pessoas: da cada d'este segue pela costa do mar a estrada geral d'esta Capitania para a Bahia (...)" (Rubim, 1840/ 2003: 17) ${ }^{5}$.

Nos cerca de cinquenta Relatórios de Presidentes da Província do Espírito Santo consultados, a Estrada Geral da Costa aparece mencionada diretamente em $30 \%$ deles. Nestes, por sua vez, são ressaltadas suas características formais como sinuosidade, estreiteza, irregularidade, com um aspecto 'quase' natural, como dando indícios de que se trata de uma forma persistente:

"Tenho mandado quebrar algumas pedras, que existem no caminho da Capichaba e que tornão difficil o transito, e continuarei á authorisar esta despesa por julgá-la indispensável, e a qual ha sido, e será dedusida da verba--Estiadas - por que considero esse caminho, como princípio da estrada geral para as villas do Norte" (Espírito Santo (Província) Presidente (Filippe Leal), 1850: 24) ${ }^{6}$.

Entretanto, mais uma vez, em nenhum momento durante a consulta destes documentos, ou mesmo de outros como relatos de viajantes, em nenhum trecho de texto identificado se pode compreender que a Estrada foi aberta durante o Império, ou que foi construída naqueles anos, ou mesmo que uma equipe de técnicos se dirigiu à campo para escolher o melhor lugar para sua construção. Antes, e pelo o contrário, parece sempre ter estado ali.... Uma vez que 'sempre' é um adverbio que se deve evitar, coloca-se a dúvida novamente sobre o tempo desta forma. Não poderia ter sido o Eixo Maruípe uma forma produzida no período colonial?

Primeiramente, reconhece-se que durante o período pré-colonial, os povos nômades e seminômades que ocupavam o território brasileiro tinham lógicas de circulação por caminhos de terra e de mar, o mesmo se dando no período colonial a partir da chegada dos 'colonizadores' portugueses (Holanda, 1994; Reis, 1968/ 2001). Estes caminhos estão indicados em cartografias e textos de forma descritiva. Contudo e infelizmente, no caso do objeto de pesquisa, as informações contidas na cartografia não foram identificadas.

Com uma estratégia de ocupação antrópica das estreitas planícies e terraços os colonos portugueses, que chegaram junto com o donatário Vasco Fernandes Coutinho, e a ordem religiosa da Companhia de Jesus se instalaram no Espírito Santo. Esta faixa de terra cujos moradores originários, os indígenas, já ocupavam desde tempos remotos com suas aldeias:

"Pelas terras desta capitania até junto do Espírito Santo, se acha uma certa nação de gentio que veio do sertão há cinco ou seis anos, e dizem que outros índios contrários destes, vieram sobre eles a suas terras, e os destruíram todos e os que fugiram são estes que andam pela costa" (Gândavo, 1576/2008: 41).

\footnotetext{
${ }^{5} \mathrm{Na}$ transcrição do Documento foi mantida a grafia original do Português Arcaico.

${ }^{6} \mathrm{Na}$ transcrição do Documento foi mantida a grafia original do Português Arcaico.
} 
O estudo arqueológico coordenado, nas décadas de 1960 e 1970, dentro do Programa Nacional de Pesquisas Arqueológicas (PRONAPA), pelo Arqueólogo e Professor Celso Perota (UFES) identificou vestígios de primitivas aldeias indígenas em Vitória. Dentre as áreas que guardam evidências materiais da presença da cultura pataxó na ilha destacam-se algumas: região do bairro Fradinhos (sítio arqueológico); proximidades do Quartel da Polícia Militar (nas imediações da Avenida Maruípe); Cemitério de Maruípe; e Morro do Macaco. Assim sendo, os fragmentos recolhidos pelos arqueólogos em suas escavações apontam para a existência de aldeias não só na colina central, mas ao longo do Eixo em estudo.

Pois se haviam os pontos de assentamento supostamente deveriam existir as linhas (caminhos) que interligavam estes pontos. Como sinalizam alguns autores como Sergio Buarque de Holanda (1994) e Gloria Kok (2009), durante o período colonial e imperial no Brasil, havia os caminhos de terra e os caminhos de mar. E alguns destes caminhos podem ter sido em parte aproveitados das trilhas estreitas (onde se andava em fila) utilizadas pelos povos indígenas, que para se deslocar por terra seguiam ora as linhas de talvegue, ora as linhas de cumeada a depender das condições tipo-mórficas do território. No caso especifico da região em estudo além da questão físico-territorial, corrobora a importância das linhas de talvegue para deslocamentos, a prática comum dos índios de caminhar em paralelo aos rios (Holanda, 1994; Kok, 2009; Perota, 1979). Então as 'rudimentares veredas' (Kok, 2009: 93-94) eram utilizadas pelas tribos para caminhar pelo território e, uma vez abertas em mata fechada, algumas parecem ter persistido formalmente:

"A transmissão dessa sabedoria indígena forneceu importantes informações sobre o território americano, desde os caminhos percorridos pelos rios até os morros e suas características. O conhecimento da topografia e geografia brasileiras permitiu aos colonos definir para os portugueses o que Claude Lévi-Strauss chama de cartografia indígena: "um acervo de informações espaciais, construído pela memória e enraizado, principalmente, nos sentidos" (Reis, 2011: 41).

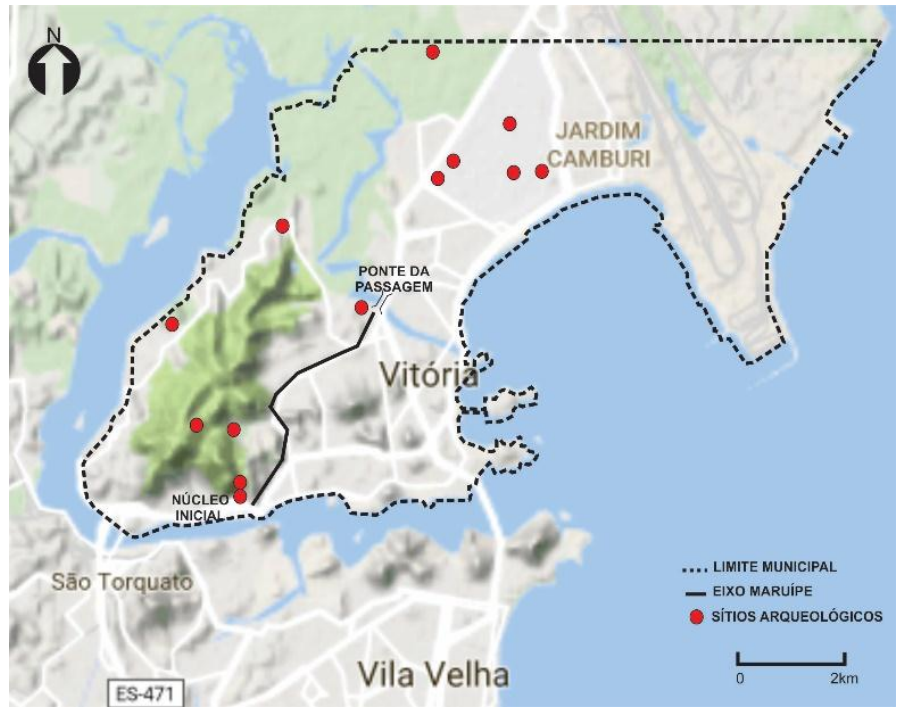

Mapa do município de Vitória, com identificação do Eixo Maruípe e da localização de sítios arqueológicos.

Fonte: Elaborado pelo autor a partir de base do Google Maps e de informação pesquisada junto ao Instituto do Patrimônio Histórico e Artístico Nacional (Superintendência no Espírito Santo).

Com tais características e aspectos formais locais, volta-se a questão inicial: de quando é o Eixo Maruípe? A pesquisa, no momento, inflete no sentido de argumentar sobre a hipótese de que o Eixo Maruípe pode ter sido, nos limites da ilha, parte de um caminho indígena entre aldeias que já se enunciava no século XVI. Este indicativo, como se nota, retrocede além do que foi proposto inicialmente mas apresenta-se de modo imponderável.

\section{RESULTADOS E DISCUSSÕES PARCIAIS}

Através desta coleção de fragmentos, é possível afirmar a existência de uma ligação terrestre entre o núcleo de povoamento inicial, em Vitória, seguindo na direção Norte, possivelmente oriundo do período colonial e que durante os séculos XVII e XVIII se estabilizou, pouco a pouco, por consequência de sua função como rota comercial. Entretanto, este não foi o único motivo de sua persistência. As características topográficas locais também influenciaram na manutenção do eixo e do trajeto da via. Assim, a partir dos dados pesquisados 
em relação ao Eixo Maruípe, como um resultado parcial da pesquisa, constata-se a existência de três escalas de persistência morfológica: a escala do território, da cidade e na região.

Quanto à persistência na escala do território, o Eixo Maruípe é um vestígio material do que teria sido uma das estradas interprovinciais do Espírito Santo, aquela denominada Estrada Geral da Costa. Descrita nos documentos como estreita, sinuosa, que corria em paralelo ou junto ao mar, sem data definida de inauguração, 'quase natural', se estendia desde o Sul e continuava a se conectar com os principais núcleos litorâneos ao Norte. Numa comparação morfológica, amparada nos documentos encontrados e na qual são consideradas as linhas de talvegue da ilha, direção, inflexões, conclui-se que o Eixo Maruípe é correspondente à uma parte da Estrada da Costa que passava por dentro da llha de Vitória. Portanto, o conjunto de vias que formam o Eixo Maruípe não foi uma criação da República, mas já existia no Império.

Entretanto, com o desenvolvimento das leituras, em algum momento da pesquisa, passou-se a acreditar que era possível retroceder no tempo ainda um pouco mais. Pelas descrições físicas desta estrada nos Relatórios e Mensagens dos Presidentes da Província do Espírito Santo não se percebia, como na descrição das demais estradas, um tom sobre as tentativas para sua abertura, os sucessos, os fracassos. Pelo contrário, havia com frequência uma abordagem sobre a necessidade de melhorar, de investir, de pavimentar, de torná-lo um eixo carroçável.

O que parece semântica poderia ser o indício de uma persistência deste objeto na escala da cidade. Esta segunda escala de persistência ampara-se nas evidências de que existia, nos limites da ilha, caminhos indígenas entre as aldeias existentes naquela pequena escala, que seguiam as linhas de talvegue em paralelo aos rios. Seguindo a direção Norte, a linha de talvegue mais evidente é justamente o encaminhamento do Eixo Maruípe, por entre os Morros São João, Romão, Cruzamento, Jucutuquara, Macaco, Engenharia. Assim passou-se a supor que o trecho da Estrada Imperial que passava por dentro da ilha poderia ser a persistência de uma antiga trilha indígena do período colonial.

Numa terceira escala de persistência, considerou-se o processo de urbanização da região Nordeste de Vitória por onde o Eixo Maruípe passa. Durante o século XX, esta região composta basicamente por duas fazendas maiores - Maruípe e Jucutuquara - foi vendida, parcelada em loteamentos, doada parcialmente ao Governo. Aos poucos, através da ação de agentes do Estado, a outrora estrada foi passando a ser denominada rua ou avenida por meio de uma série de melhoramentos. A toponímia estrada se apagou, mas não seu direcionamento ou sua materialidade. As transformações ocorrem? Sim e não. Concomitante às mudanças, o processo da permanência e persistência morfológica também ocorreu.

Esta linha de talvegue que recorta o território da ilha de Vitória, durante a República, num processo de acumulação de intervenções de projetos urbanos foi retificada, alargada, pavimentada e recebeu mobiliários urbanos de toda sorte. A toponímia de Estrada de Maruípe passa para as atuais Avenidas Vitória, Paulino Muller, Maruípe, Fernando Ferrari, mas morfologicamente seu eixo persiste. Continua acompanhando em paralelo as linhas topográficas e os cursos d'água (mesmo que ocultos), o nível de cota continua sem grandes alterações, a direção se mantém ligando o núcleo urbano central e à Ponte da Passagem, e apesar da formação sucessiva do tecido urbano do entorno, não foi alterada.

Acredita-se, com isso, que esta forma material que veio do passado atravessando as camadas do tempo, continua no presente. Torna-se, mais um exemplo dentre outros que ocorrem (como visto na Literatura através dos estudos da Broadway, em Nova lorque, ou do Caminho Peabiru, em São Paulo), da forma indelével.

\section{CONSIDERAÇÕES FINAIS}

Ao longo da pesquisa que se desenvolve no Doutorado, e encontra-se em estado intermediário, o objeto de verificação da tese foi ganhando protagonismo. Na primeira fase da pesquisa, considerada como os dois primeiros anos até a Banca de Qualificação, foram fundamentais a seleção de leituras (recorte teórico) e a recolha de documentação em entidades custodiadoras sediadas no Estado do Espírito Santo.

Esta leitura foi norteada pela área temática da Morfologia, englobando autores também da História Urbana, e tornou-se fundamental tanto na construção do quadro teórico, quanto na identificação de estudos de caso semelhantes. Desta fase destacou-se um interesse específico, já explicitado no artigo, sobre o tempo das formas. Quão duráveis são as formas? Existem padrões para esta duração? Por que e como duram as formas? Qual o elemento mais persistente? 
A recolha da documentação também trouxe informações e perguntas. Ao percorrer os arquivos o foco em destaque era localizar as plantas cadastrais da cidade de Vitória e cartografias complementares aos dados sobre o traçado urbano. Ao olhar para estes documentos despontava uma dúvida: seria possível identificar através da análise cartográfica as formas mais antigas? Ao mesmo tempo construía-se uma certeza: com aqueles documentos era possível fazer uma pesquisa com perfil morfológico, comparativo e retrospectivo.

Na segunda fase da pesquisa, ou seja, após a Defesa de Qualificação a dedicação foi sobre trabalhar com a documentação recolhida, fundamentada no quadro teórico construído. Nesta movimentação ganhou protagonismo o interesse por investigar a persistência da forma dos caminhos antigos, tendo como recorte físico territorial a parte insular de Vitória.

A aplicação da teoria à prática não se configurou como uma via de mão única. Os exemplos e conceitos estudados contribuíram à análise territorial, mas o contrário também foi verdadeiro. A análise do objeto retroalimentou a teoria. Neste sentido apontam-se como perspectivas futuras as contribuições sobre as singularidades na escala de Vitória e sobre as generalidades com a inserção deste estudo na discussão teórica sobre a longevidade da forma.

Os estudos sobre o Caminho Peabiru, que na sua escala continental latino-americana ia desde o Peru até o Brasil, ou do Caminho dos Goyases que percorria os Estados de São Paulo e Goiás são referenciais fundamentais na América Latina. Os estudos de caso europeus sobre as rotas romanas, os itinerários primitivos em Lisboa, os caminhos agrícolas no traçado catalão assim como ofereceram indicativos metodológicos e teóricos, na fase inicial da pesquisa, também poderão ser confrontados e comparados com os resultados obtidos.

Acredita-se que a análise urbana deve ser acrescida de camadas de interpretação, daquelas nas quais o arquiteto expressa seu saber. A identificação de atores e agentes da forma urbana, o interesse sobre quem produziu a forma (e quais circunstâncias políticas e econômicas desta produção), tem equivalente relevância em relação à verificação sobre o que foi produzido, com qual geometria ou o processo com que esta forma foi produzida. O estudo da morfologia é, em vista disso, tanto uma porta aberta para entender o presente através do passado, quanto uma oportunidade para compreender e desenhar o futuro.

\section{AGRADECIMENTOS}

Este artigo é parte de pesquisa de Doutorado em andamento na Universidade Presbiteriana Mackenzie São Paulo, sob orientação da Profa. Dra. Maria Isabel Villac, e recebe apoio institucional do Mack-pesquisa; da Prefeitura Municipal de Vitória e do FACITEC (Fundo de Apoio à Ciência e Tecnologia - Vitória).

\section{REFERÊNCIAS}

CONZEN, MRG. (1960). Alnwick, Northumberland: a study in town plan analysis. Londres: Institute of British Geographer.

- (2004). Thinking about urban form. Papers on Urban Morphology, 1932-1998. Editado por Michael P. Conzen. Oxford: Peter Lang Publishers.

DIAS COELHO, C. (org.). (2014). Cadernos de Morfologia urbana: o tempo e a forma. Volume 2. Lisboa: Argumentum, 2014.

Espírito Santo (Província) (1850) Relatório com que o Exm. Sr. Filippe José Pereira Leal Presidente da Província do Espírito Santo abriu a sessão ordinária da respectiva Assembleia Legislativa, no dia vinte e cinco de julho do corrente ano.

GÂNDAVO, P. de M. (1576/ 2008). Tratado da Terra do Brasil; história da província Santa Cruz, a que vulgarmente chamamos Brasil. Brasília: Senado Federal, Conselho Editorial.

HOLANDA, S. B. de. (1994). Caminhos e fronteiras. São Paulo: Companhia das Letras.

KOK, G. (2009) Vestígios indígenas na cartografia do sertão da América portuguesa. Anais do Museu Paulista (São Paulo), Vol.17, n.2, 91-109.

KOSTOF, S. (1999/ 2009). The city shaped: urban patterns and meanings through History. London: Thames \& Hudson.

KROPF, K. (2009). Aspects of urban form. Urban Morphology, Vol. 13 (2), 105-120.

LAVEDAN, P. (1926). Qu'est-ce que I'urbanisme? Paris: Henri Laurens.

MORRIS, A. E. J. (1979). Historia de la forma urbana. Barcelona: Gustavo Gilli. 
PEROTA, C. (1979). Sítios arqueológicos e acervo pré-histórico no Espírito Santo. Revista Fundação Jones dos Santos Neves (Vitória), Ano II, no.4, 19-20.

PINON, P. (2008). Défense et illustration de la "Loi de persistance du plan": Le problème de la survivance du tracé des rues dans les villes françaises d'origine antique. En: BALLET, P.; DIEUDONNÉ-GLAD, N.; SALIOU, C. (Org.). La Rue dans l'Antiquité: Définition, aménagement, devenir. (129-140). Rennes: Presses Universitaires de Rennes.

PORTAS, N. (2005). Os tempos das formas. Volume 1: a cidade feita e refeita. Guimarães: Univ. do Minho.

REIS, F. P. (2011). A serra das Esmeraldas: cartografia, imaginário e conflitos territoriais na Capitania do Espírito Santo (século XVII). Mestrado em História Social. São Paulo: Pontifícia Universidade Católica de São Paulo.

REIS, N. G. (1968/ 2001). Contribuição ao estudo da evolução urbana do Brasil (1500/1720). São Paulo: Pini.

- (1970/ 2014). Quadro da arquitetura no Brasil. São Paulo: Perspectiva.

- (2004). São Paulo: Vila Cidade metrópole. São Paulo: Ministério da Cultura.

- (2014). Caminho do Anhanguera. São Paulo: Via das Artes.

RUBIM, F. A. (1840/ 2003). Memorias para servir à História até o anno de 1817, e breve noticia estatística da Capitania do Espírito Santo, porção integrante do Reino do Brasil, escriptas em 1818 e publicadas em 1840 por hum capixaba. Lisboa: Imprensa Nevesiana.

SARTORIO, E. A. (2007). A trilha sagrada. Volume 1: Anatomia histórica das estradas. Vitória: Ed. do autor.

WAISMAN, M. (2013). O interior da História. Historiografia arquitetônica para uso de latino-americanos. São Paulo: Perspectiva. 